This item was submitted to Loughborough's Research Repository by the author.

Items in Figshare are protected by copyright, with all rights reserved, unless otherwise indicated.

\title{
Tuning morphology in active pharmaceutical ingredients: controlling the crystal habit of lovastatin through solvent choice and non-size-matched polymer additives
}

\section{PLEASE CITE THE PUBLISHED VERSION}

https://doi.org/10.1021/acs.cgd.0c00470

\section{PUBLISHER}

American Chemical Society (ACS)

\section{VERSION}

AM (Accepted Manuscript)

\section{PUBLISHER STATEMENT}

This document is the Accepted Manuscript version of a Published Work that appeared in final form in Crystal Growth \& Design, copyright $\odot$ American Chemical Society after peer review and technical editing by the publisher. To access the final edited and published work see https://pubs.acs.org/doi/10.1021/acs.cgd.0c00470.

\section{LICENCE}

CC BY-NC-ND 4.0

\section{REPOSITORY RECORD}

Hatcher, Lauren E, Wei Li, Pollyanna Payne, Brahim Benyahia, Chris Rielly, and Chick C Wilson. 2020.

"Tuning Morphology in Active Pharmaceutical Ingredients: Controlling the Crystal Habit of Lovastatin Through Solvent Choice and Non-size-matched Polymer Additives". Loughborough University.

https://hdl.handle.net/2134/12977585.v1. 


\title{
Tuning Morphology in APIs: Controlling the Crystal
}

\section{Habit of Lovastatin through Solvent Choice and}

\section{Non-Size-Matched Polymer Additives}

Lauren E. Hatcher, ${ }^{+, * *}$ Wei Li ${ }^{\S}$ Pollyanna Payne, ${ }^{+, *}$ Brahim Benyahi, ${ }^{\S}$ Chris D. Rielly, ${ }^{\S}$ Chick C. Wilson. ${ }^{\dagger+t}$

${ }^{\dagger}$ Future Continuous Manufacturing and Advanced Crystallisation (CMAC) Research Hub at the University of Bath, Bath, BA2 7AY, UK

†Department of Chemistry, University of Bath, Bath, BA2 7AY, UK

${ }^{\S}$ Department of Chemical Engineering, Loughborough University, Loughborough, LE11 3TU, UK

\begin{abstract}
Additive crystallization routes to control the crystal habit of the active pharmaceutical ingredient (API) lovastatin are presented, at small scale up to $25 \mathrm{~mL}$. Lovastatin is an archetypical example of an API that forms needle-like crystals via solution- based recrystallization, causing issues for downstream pharmaceut- ical processing stages. In this work, the size and shape of lovastatin needles are shown to be subtly influenced by the crystallization solvent, concentration, and crystallization procedure, with moderately hygroscopic ethyl acetate solvent producing needles
\end{abstract}


with improved aspect ratios in comparison to the acetone/water mixtures primarily used for industrial recrystallization. Further, the inclusion of soluble, non-size-matched polymer additives, at very low concentrations $(0.5 \mathrm{wt} \% / \mathrm{wt})$, into the solution has a pronounced impact on the crystal habit. While the inclusion of the hydrophilic polymer poly(ethylene glycol) promotes the formation of even longer, thinner needles than those formed by nonadditive routes, the use of hydrophobic poly(propylene glycol) improves the habit from needles toward plate-like crystals. The product materials are analyzed by a combination of microscopy, thermal analysis, and diffraction-based techniques, with the latter enabling rationalization of the habit control via identification of the prominent crystal faces and growth directions with respect to the underlying crystal structure.

\section{INTRODUCTION}

Lovastatin, or Mevinolin, is one of a number of active pharmaceutical ingredients (APIs) in the statin family, prescribed for the treatment of hypercholesterolemia (Figure 1). The drug was first discovered as a naturally occurring fungal metabolite ${ }^{1}$, whose powerful potential to reduce low density lipoprotein (LDL) cholesterol levels was first realised in the early $1980 \mathrm{~s}^{2}{ }^{2}$ As such, lovastatin is typically produced on an industrial scale via biosynthetic fermentation routes, although a number of other synthetic pathways have also been investigated. ${ }^{3-6}$ Despite its benefits, lovastatin exhibits high hydrophobicity and as a result is designated a Class II drug substance under the Biopharmaceutics Classification System (BCS), ${ }^{7,8}$ reflecting its high permeability but low solubility. Lovastatin thus displays poor bioavailability and the improvement of this property is a key focus for research. ${ }^{9-11}$ Another limitation, from a pharmaceutical processing perspective, is lovastatin's propensity to form needle-like crystals on crystallization from solution. As 
recrystallization from alcohol or acetone/water mixtures is a primary purification route for lovastatin in industry, ${ }^{3}$ this is a particular problem. Needle-like crystals are well-known to cause particular issues for downstream pharmaceutical processes, including poor filtration, flowability and particle breakage. ${ }^{12,13}$ Studies aimed at controlling the crystal habit of lovastatin are therefore necessary to improve its viability in a competitive statin drug market.

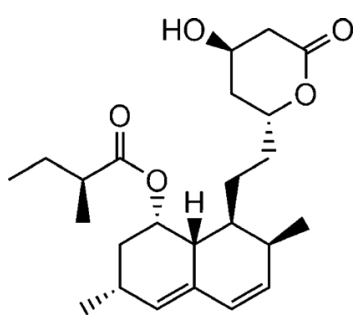

Figure 1. Molecular structure of lovastatin (Mevinolin).

The external shape of a crystal, or its habit, can be influenced by the growth conditions during the recrystallization process. In general terms, a crystal face with large area will correspond to a slower growth rate perpendicular to the plane of that face, while faces with small areas indicate fast crystal growth in a perpendicular direction. ${ }^{14}$ Many researchers have aimed to influence crystal size and shape by controlling the relative growth rates of the individual faces via a number of routes, including temperature cycling, ${ }^{15-17}$ solvent selection and continuous crystallization methods. ${ }^{18,} 19$ The effect of small concentrations of impurities on the crystallization process is also of particular interest, as trace levels of impurities from prior reaction or purification steps often remain present in a synthesised API material. ${ }^{20}$ The intentional addition of low concentrations of impurities is often referred to as additive crystallization, and there are many instances where additive methods have been employed to tune crystal habit and morphology in the literature. 
Additives used in crystallization processes can be broadly categorized according to their solubility. ${ }^{21}$ Insoluble additives often influence nucleation and crystal growth by acting as templates or scaffolds on which heterogeneous nucleation can occur. The presence of soluble additives can also have an impact on the crystallization process and the end product crystals, either in terms of their habit, ${ }^{14,22}$ size $^{23-25}$ or solid form (e.g. by controlling the polymorphic form). ${ }^{22,26 \text {, }}$ ${ }^{27}$ Examples of soluble additives in the literature include: simple inorganic ions (e.g. $\mathrm{Li}^{+}$or $\left.\mathrm{K}^{+}\right),{ }^{28}$ low mass organic additives, ${ }^{20}, 26,29,30$ surfactants, ${ }^{23}, 31,32$ polymer additives (including homopolymers ${ }^{22,} 30,33$ and block co-polymers ${ }^{14}, 15,34$, and bio-/macromolecules. ${ }^{21}$ For the crystallization of APIs, where the choice of additive must be restricted to compatible materials e.g. those listed on the US Food and Drug Administration's Generally Recognised As Safe (GRAS) list, low mass organics, polymers or surfactant additives are most commonly used.

There are several examples where low mass organic additives of a similar size or structure to the target molecule have been used to modify crystal shape. These include seminal studies such as the crystallization of benzamide in the presence of benzoic acid ${ }^{35}$ and of urea from solutions containing trace amounts of biuret, ${ }^{36}$ as well as more recent reports. ${ }^{30,37,38}$ Investigations have indicated that structurally-similar additives are particularly effective at inhibiting nucleation, ${ }^{20,30}$ which in turn may influence product crystal habit, size or polymorphic form. As well as experimental studies, computational modelling investigations into the effects of structurally-similar additives on crystal shape are also reported. ${ }^{39,40}$ Despite these successes, due to their similarity in terms of steric bulk and the likelihood of complementary associative interactions (e.g. similar functional groups and/or hydrogen bond donors/acceptors), there is a higher risk of additive inclusion into the crystal bulk, leading to a change in solid form that may be undesirable. 
One route to mitigate such issues is the use of non-size-matched additives. Due to their differing size and steric demands it is much less likely that larger soluble additives, e.g. polymers and surfactants, will be incorporated into the API crystal lattice. Many GRAS polymers and surfactants are also used in later secondary processing steps, or as excipients in final drug formulations, thus their presence during crystallization presents fewer regulatory concerns. Prior examples of the use of polymer and surfactant additives to control API crystal shape and size include, among others, studies with succinic acid, ${ }^{14}, 15$ carbamazepine,${ }^{37}$ salbutamol sulfate,${ }^{41}$ naproxen,,${ }^{42}$ and piroxicam,${ }^{43}$ while there are also examples of tailor-made polymer additives designed specifically for control of API crystal habit. ${ }^{44}$ Though some studies have investigated the effect of these non-size-matched additives on nucleation, ${ }^{30}$ there is greater focus in the literature on their influence over crystal growth kinetics. There is particular evidence that hydrogen donor and/or acceptor capabilities have a bearing on the additive's ability to influence growth rates in certain directions, ${ }^{14,30,37,41}$ leading to the expectation of an interaction between the additive and specific crystal faces. Such deductions are predominantly the result of inferred experimental evidence from spectroscopic studies and/or post-processing steps. ${ }^{14,37}$ However, direct experimental observation of additive adsorption at a specific surface is yet to be realised, as is any deduction of a general mechanism for such a process.

In this study we report a solvent-controlled effect on the crystal habit of lovastatin with ethyl acetate at small crystallization scales $(5-25 \mathrm{~mL})$, both under evaporative and temperaturecontrolled crystallization conditions. We also report the influence of low concentrations of nonsize-matched additives poly(ethyleneglycol) [PEG] and poly(propyleneglycol) [PPG] on lovastatin crystal size and habit, and use a combination of solubility, microscopy, diffraction, and thermal analysis measurements to infer the likelihood of additive-API interaction at the natural crystal faces. 


\section{EXPERIMENTAL SECTION}

Lovastatin was purchased from Molekula, while poly(propyleneglycol) 4000 [PEG] and poly(ethyleneglycol) 200 [PEG] were obtained from Sigma Aldrich and used as received. All solvents were reagent grade and were used as purchased, without further purification.

Solubility and MSZW Measurements. Solubility and metastable zone width (MSZW) data for both lovastatin in ethyl acetate and lovastatin in the presence of $0.5 \%$ PEG and PPG polymers, respectively, were carried out at the University of Strathclyde using a Technobis Crystallization Systems Crystal16 benchtop crystallization system. The Crystal16 uses turbidity and in-line imaging methods to detect dissolution (or "clear") points and nucleation (or "cloud") points for a solution as it is exposed to a temperature cycling regime. $1.5 \mathrm{~mL}$ vials containing lovastatin solutions at a range of concentrations were prepared for each experiment and were repeatedly cycled between $20^{\circ} \mathrm{C}$ and $65^{\circ} \mathrm{C}$ at a heating and cooling rate of $1{ }^{\circ} \mathrm{C} / \mathrm{min}$. All vials were stirred throughout the analysis via magnetic stirrer bars operating at $700 \mathrm{rpm}$. The data were analysed using the software CrystalClear (Avantium Technologies: version 1.0.1.614).

Powder X-ray diffraction (PXRD). PXRD data were collected on lightly ground samples using

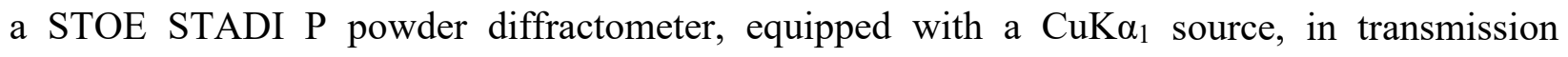
geometry. Data were collected at ambient temperature, between $2^{\circ}$ and $75^{\circ}$ in $2 \theta$, using a Dectris Mythen $1 \mathrm{~K}$ detector. The data were collected and analysed using the WinXPOW powder diffraction software suite (STOE; version 3.6.0.1). 
Single crystal X-ray diffraction (SCXRD) and crystal face indexing. SCXRD data were recorded using a dual-source Rigaku Oxford Diffraction Gemini A Ultra diffractometer, equipped with an Atlas CCD detector. The system included an Oxford Cryosystems Cryojet-XL liquid nitrogen flow device for sample temperature control, and a microscope camera allowing high resolution images of the crystal sample to be obtained for crystal face indexing. Data collection, indexing and integration, as well as crystal face indexing procedures, were carried out using the software CrysAlis ${ }^{\mathrm{PRO}}$ (Rigaku Oxford Diffraction; version 39.46), following the software's standard protocols.

Evaporative crystallization experiments at the $5 \mathrm{~mL}$ scale. Initial batch evaporative crystallization studies with lovastatin in (i) 1:1 acetone:water and (ii) ethyl acetate were prepared as follows. A small portion (c.a. $50 \mathrm{mg}$ ) of lovastatin powder was weighed into $1.7 \mathrm{~mL}$ crystallization vials and dissolved in the minimum volume of solvent $(>3 \mathrm{~mL})$ by warming the solutions to $35^{\circ} \mathrm{C}$, with stirring, for c.a. 15 mins. The solutions were cooled and the stirrer bars removed, then filtered into fresh vials and capped with lids containing 7 holes. The vials were then allowed to evaporative slowly at a constant, controlled $25^{\circ} \mathrm{C}$ for c.a. 1 week. Any suitable single crystal products were then collected and analysed.

Temperature cycling crystallization experiments at the $20 \mathrm{~mL}$ scale. Batch temperature cycling crystallization studies with lovastatin in ethyl acetate, both with and without polymer additives, were conducted using a Cambridge Reactor Design (CRD) Polar Bear Plus crystalliser. Lovastatin and, where relevant, the chosen polymer additive, were weighed into $22 \mathrm{~mL}$ vials at ratios calculated according to the intended API:polymer ratios. $20 \mathrm{~g}$ of ethyl acetate solvent was then added to make up solutions of the chosen concentration levels (either $\mathrm{T}_{\mathrm{sat}}=30^{\circ} \mathrm{C}$ or $50{ }^{\circ} \mathrm{C}$ ). All $20 \mathrm{~mL}$ crystallizations were agitated by overhead stirring, implemented using magnetically 
controlled overhead impellers from Technobis. For the $\mathrm{T}_{\text {sat }}=30{ }^{\circ} \mathrm{C}$ experiments, following an initial heating ramp to $40{ }^{\circ} \mathrm{C}$ to ensure complete dissolution, the vials were cycled between $20^{\circ} \mathrm{C}$ and $30^{\circ} \mathrm{C}$ for a total of 10 cycles, with continuous overhead stirring throughout (see Figure 2, top). For the $\mathrm{T}_{\text {sat }}=50{ }^{\circ} \mathrm{C}$ experiments, a consistent, wider temperature cycle between 50 and $5{ }^{\circ} \mathrm{C}$ was maintained throughout the crystallization experiment (see Figure 2, bottom).
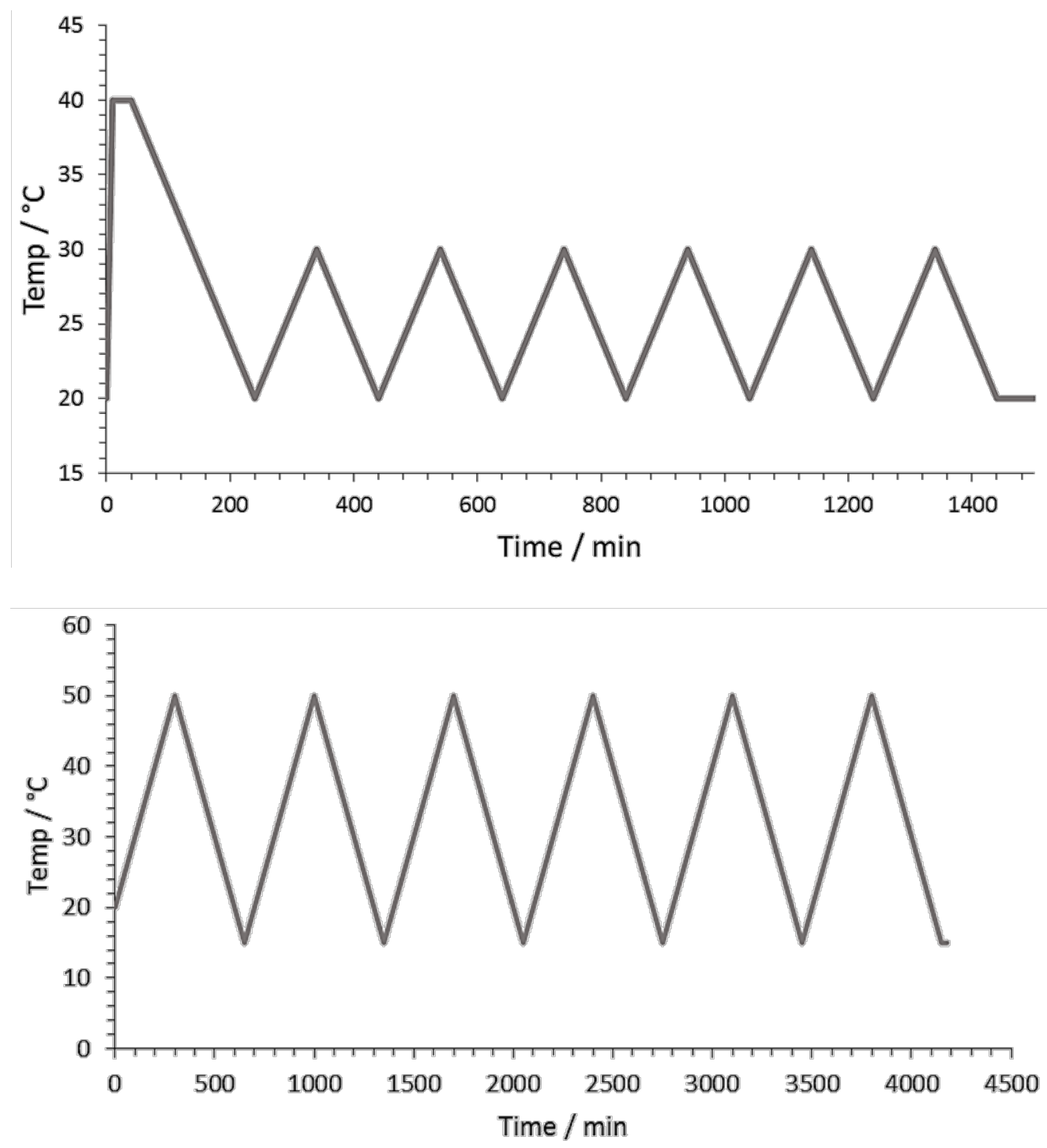

Figure 2. Temperature cycling profile implemented on the CRD Polar Bear Plus for temperature cycling studies at $\mathrm{T}_{\mathrm{sat}}=30{ }^{\circ} \mathrm{C}$ (top) and $\mathrm{T}_{\mathrm{sat}}=50^{\circ} \mathrm{C}$ (bottom) 


\section{RESULTS AND DISCUSSION}

Evaporative crystallizations at the $5 \mathrm{~mL}$ scale. Initial batch evaporative crystallization screens were conducted with lovastatin in a range of solvents to assess the effect of solvent on the crystal morphology at small scale. The majority of the solvents tested produced thin, needle-like crystals typical of lovastatin crystals reported in the literature, ${ }^{3}$ the most representative of these being needles crystallised from a 1:1 acetone:water mix (Figure 3, left). However, crystallizations from ethyl acetate solutions produced needles that are observed to be considerably larger and thicker by polarised light microscopy (PLM), indicating an improved aspect ratio (Figure 3, right).
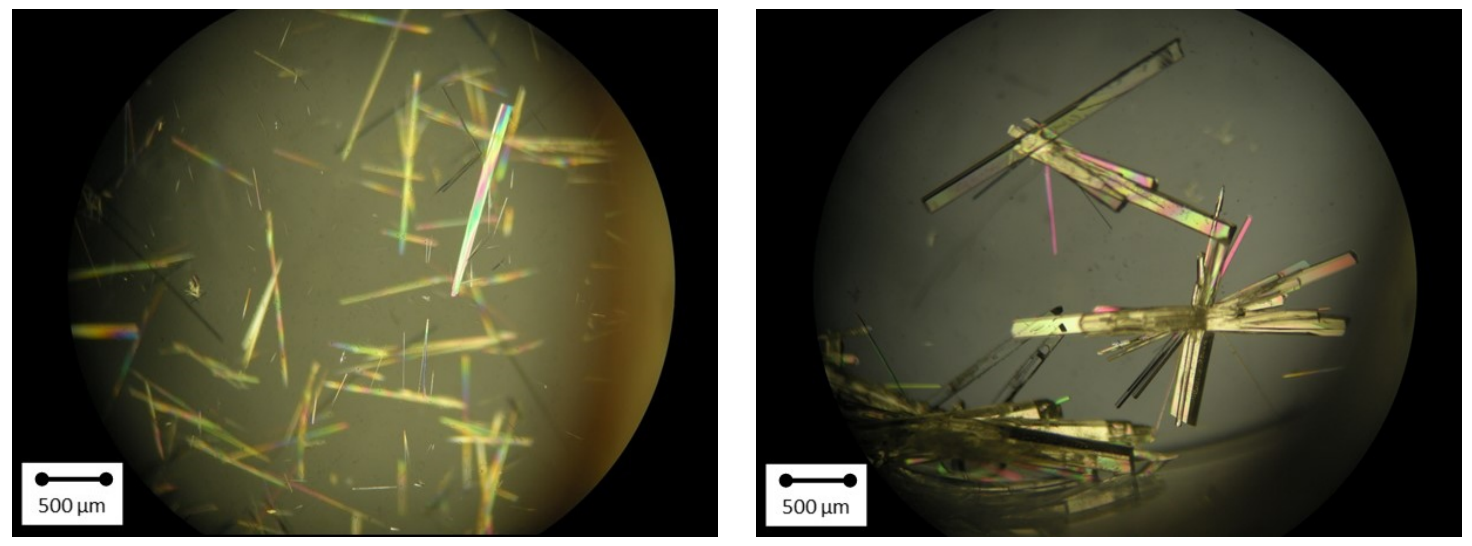

Figure 3. Crystals of lovastatin formed by slow evaporation from a solution of 1:1 water:acetone (left) and ethyl acetate (right)

PXRD and DSC measurements confirm that no structural transformation occurs on crystallization from ethyl acetate (see Supporting Information), with both analyses indicating crystal lattice and structure matching those taken from a sample of lovastatin starting material. 
Crystal Face Indexing. A representative crystal from both the 1:1 acetone:water and ethyl acetate evaporative crystallizations was also analysed by single crystal X-ray diffraction (SCXRD). A unit cell determination confirmed that the unit cell parameters match the known structures of lovastatin recorded in the Cambridge Structural Database (CSD), ref. codes CEKBEZ and CEKBEZ01, further confirming that the change in crystal habit is not accompanied by a structural transformation.

The natural crystal faces for each sample were then determined experimentally, via crystal face indexing methods using CrysAlis ${ }^{\mathrm{PRO}}$ software (Rigaku Oxford Diffraction; version 39.46). Figure 4 compares the lovastatin needle habits produced from each solvent system.
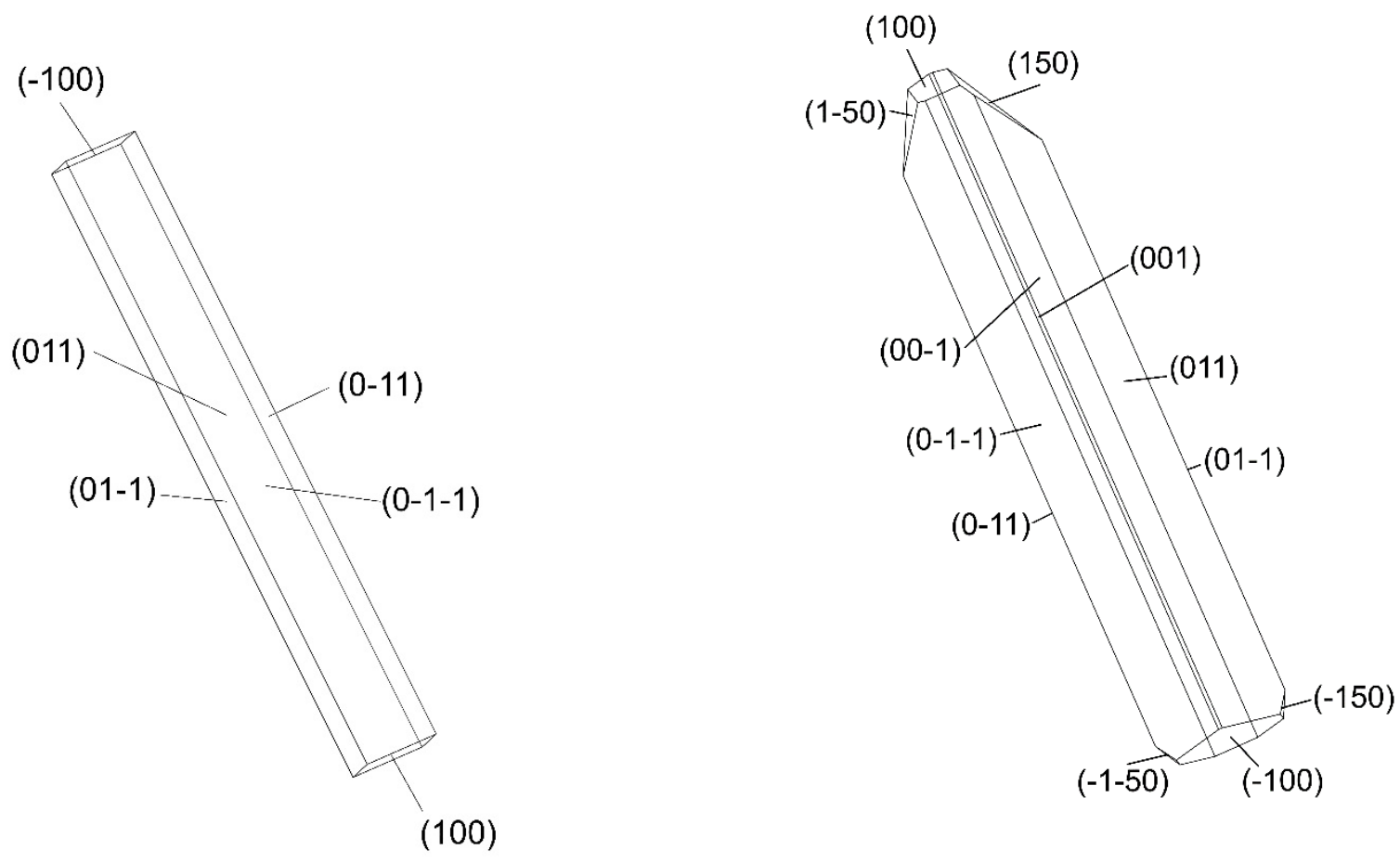

Figure 4. Natural crystal faces of lovastatin needles grown from a 1:1 water:acetone (left) and ethyl acetate (right) solutions by slow evaporation, determined by crystal face indexing methods 
Crystal face indexing confirms that both needles grow quickly along the crystallographic $a$-axis direction, with small [100] needle capping faces formed in both instances. This observation is entirely in-line with recent computational morphology studies on lovastatin needles in the literature. ${ }^{45}$ The thin needles formed from acetone/water display squared-off ends at the [100] faces and show very little significant growth in either the [010] or [001] directions, with the more prominent equatorial faces assigned to [011] and [01-1] Miller indices. The same dominant crystal faces are observed for the ethyl acetate needles, however additional [001] faces can also be identified, indicating that the increased thickness observed for these needles results from improved crystal growth in the crystallographic $c$-axis direction. The ends of the ethyl acetate needles are also observed to be bevelled, with prominent [ $\left.\begin{array}{lll}1 & 5 & 0\end{array}\right]$ and [ $\left.\begin{array}{lll}1 & -5 & 0\end{array}\right]$ facets observed. These bevelled edges are also similar to predictions of the morphology of lovastatin contact surfaces in the literature..$^{45}$
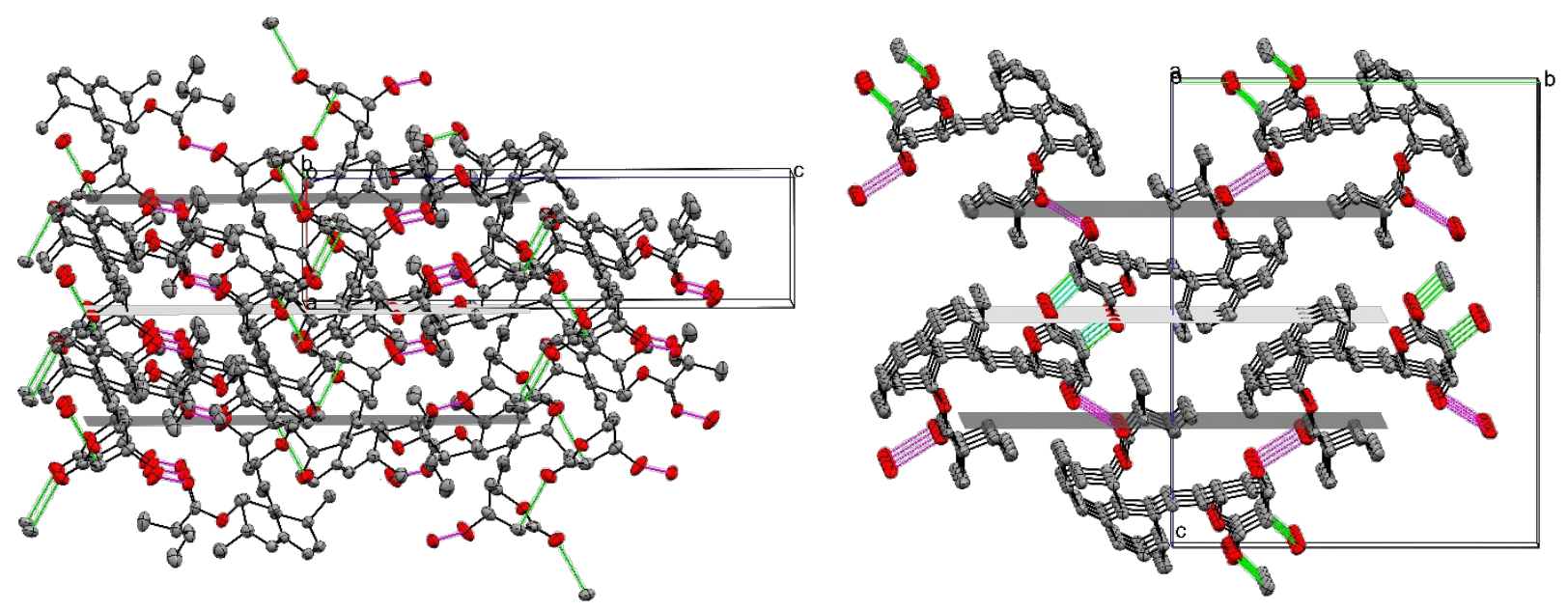

Figure 5. Plane slices through the lovastatin crystal structure (CEKBEZ01), showing the prominent functional groups intersected by the [100] crystal faces (left) and [001] crystal faces 
(right): formal $\mathrm{O}-\mathrm{H} \ldots \mathrm{O}$ hydrogen bonds represented in magenta, weak C-H... $\mathrm{O}$ hydrogen bonds represented in green and hydrogen atoms removed for clarity

As X-ray diffraction is a bulk structure determination technique, it is not possible to directly visualize the real surface terminations of the crystal. However, by overlaying Miller plane slices with the underlying lovastatin crystal structure in the CCDC software Mercury, ${ }^{46}$ it is possible to infer which key functional groups may be present at the real crystal faces. For example, where (100) Miller planes intersect terminal $\mathrm{OH}$ groups, we can infer that it is likely $\mathrm{OH}$ functionalities will be present at the real surface terminations on the (100) crystal face.

Figure 5, left, shows the planes associated with the [100] needle capping faces intersecting the structure. These faces run approximately parallel to the O-H...O hydrogen bonding direction (magenta contacts) and do not intersect them. Some weaker C-H...O contacts (shown in green) do appear to be intersected by the [100] planes, however the vast majority of the groups intersected appear to contain aliphatic $\mathrm{C}-\mathrm{H}$ bonds. This would indicate that generally non-polar functional groups are expected to be present at the [100] faces, suggesting that the fast-growing needle capping faces are likely to be hydrophobic.

Figure 5, right, shows that the [001] faces, which are prominent only in the thicker ethyl acetate needles, primarily intersect strong $\mathrm{O}-\mathrm{H} . . . \mathrm{O}$ hydrogen bonding interactions as well as the weaker $\mathrm{C}-\mathrm{H} . . . \mathrm{O}$ hydrogen bonds. This analysis indicates that polar functional groups are likely to be exposed at the [001] faces which would thus be expected to display hydrophilic properties. 
This analysis could suggest why ethyl acetate promotes thicker needles with increased growth in the [001] direction, while acetone/water does not. Ethyl acetate is known to be a fairly nonhygroscopic solvent, and thus will contain very much lower amounts of water than the acetone/water solvent mixture. Excess water molecules in the acetone/water mixture could be interacting with the hydrophilic [001] faces, blocking the approach of lovastatin molecules and thus limiting the growth along the $c$-direction. An argument based on the relative polarity of the two solvent systems can also be made: ethyl acetate, as an organic solvent, is less polar than an acetone/water mixture, and our prior work has indicated that apolar solvents can improve the aspect ratio of lovastatin needle crystals. ${ }^{45}$

Choice of additives. Non-size-matched additives were chosen by reference to literature studies, where API crystal habit and growth conditions have been successfully controlled using large polymer additives, ${ }^{14,15}$ and from a small available library of polymer additives. Building on the results of crystal face indexing studies, polymers with both hydrophilic (PEG- 200) and hydrophobic (PPG-4000) properties were selected to allow further investigation of how hydrophilic/phobic components can affect the lovastatin needle thickness. While PEG is known to show hydrophilic behavior, including good solubility in water, PPG polymers with higher molecular weights (>700-1000) display hydrophobic properties. ${ }^{14,48}$

Solubility and Metastable Zone Width measurements. To assist the design of additive controlled crystallizations, solubility and metastable zone width (MSZW) measurements were carried out for lovastatin in ethyl acetate, both with and without the presence of PEG and PPG additives. The solubility trend compares reasonably well to literature data for lovastatin in ethyl acetate, though differing methods were utilised. ${ }^{47}$ Most importantly, Figure 6 shows that lovastatin solubility is largely unaffected by the inclusion of $0.5 \% \mathrm{wt} / \mathrm{wt}$ of either polymer additive, with all 
three experiments producing solubility trends that are largely similar. The MSZW for lovastatin is also largely unaffected by the presence of either additive (see Supporting Information).

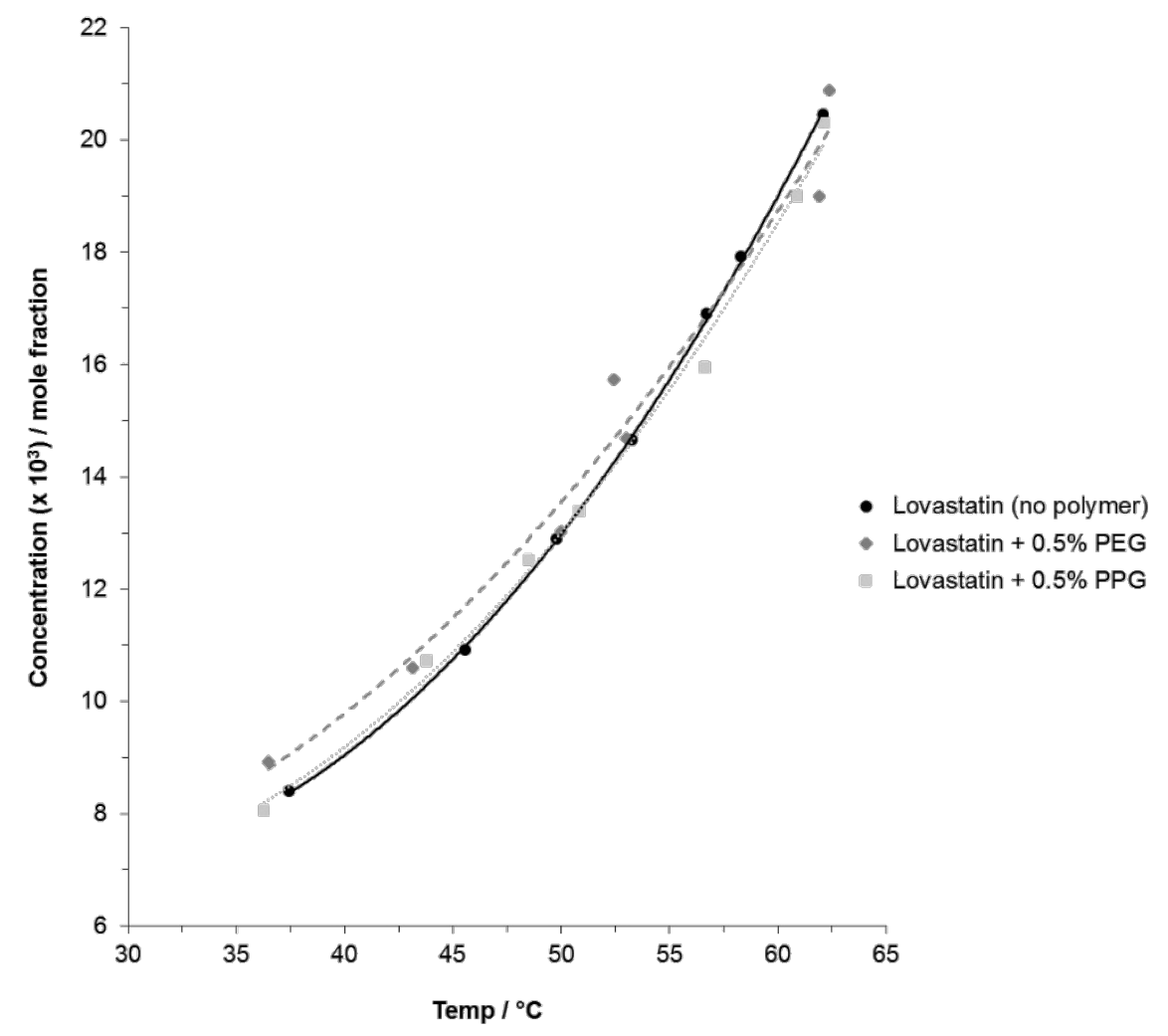

Figure 6. Solubility curves for lovastatin in ethyl acetate with no polymer additive, in the presence of $0.5 \%$ PPG additive and in the presence of $0.5 \%$ PEG additive

Temperature cycling experiments in ethyl acetate $(3.2 \% \mathrm{~m} / \mathrm{m})$. To ensure that the observed crystal faces from evaporative crystallisation were not the result of any crystal growth at the surfaces of the crystallization vessel, temperature cycling crystallizations were next conducted at the $20 \mathrm{~mL}$ scale, utilising overhead stirring methods. Temperature cycling experiments were first carried out in pure ethyl acetate solution; such methods have previously been shown to influence API crystal shape. ${ }^{15}$ To investigate this, the effect of moving to a non-evaporative crystallization method on the lovastatin crystal morphology must first be assessed. Using the solubility data 
(Figure 6) as a guideline, test experiments were first carried out at different lovastatin concentration levels of $4.6 \%, 3.2 \%, 2.2 \%$, and $1.6 \% \mathrm{~m} / \mathrm{m}$ to allow optimum conditions to be selected. 2. All vials produced needle-like crystals of similar habit to initial evaporative crystallizations from ethyl acetate, although the crystals are generally smaller by cycling methods. This may be due to the faster crystallization time, or it may be a result of introducing agitation. While the evaporative crystallizations were not stirred, the introduction of overhead stirring here could lead to attrition and, from this, a reduction in particle size. Following these initial test experiments, a concentration of $3.2 \% \mathrm{~m} / \mathrm{m}$ (equating to a saturation concentration at $30{ }^{\circ} \mathrm{C}$ ) was chosen for future experiment runs, as this gave the most uniform needle shapes (Figure 7).

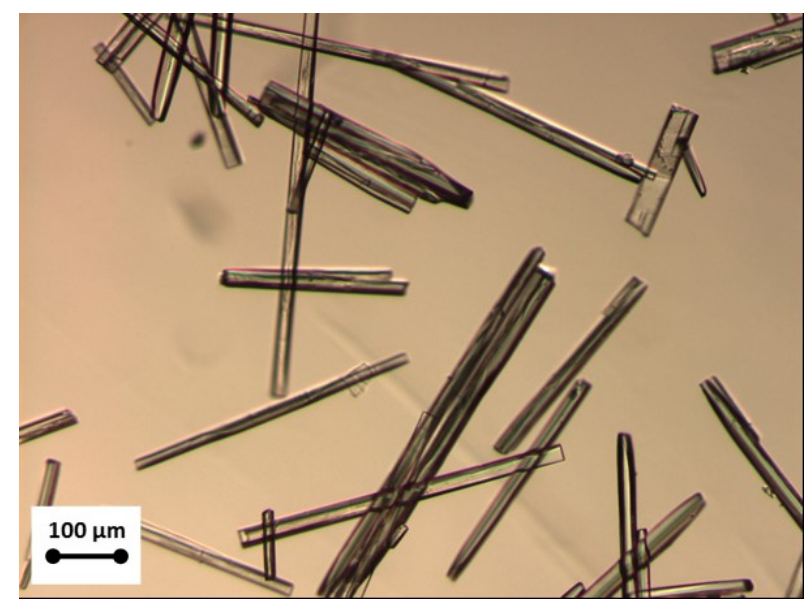

Figure 7. Crystals of lovastatin formed by temperature cycling crystallization studies in ethyl acetate at a concentration of $3.2 \% \mathrm{~m} / \mathrm{m}$ with overhead stirring

Temperature cycling experiments in the presence of different polymer additives, $3.2 \% \mathrm{~m} / \mathrm{m}$. The same experimental conditions were then used for lovastatin temperature cycling crystallizations in the presence of either $0.5 \%$ PEG or $0.5 \%$ PPG polymer additive. On the addition of hydrophilic PEG the lovastatin needles formed were longer and thinner, as confirmed by polarized light microscopy (PLM), in comparison to pure ethyl acetate control crystals grown 
under the same conditions (Figure 8, left). By contrast, the addition of hydrophobic PPG promoted formation of larger, plate-like lovastatin crystals (Figure 8, right) of considerably different habit to the needle-like materials observed so far. All product crystals from these polymer screening tests were analyzed by PXRD and DSC methods, which confirm that no structural transformation has occurred that could be responsible for the morphology changes (see Supporting Information). The crystallization yields for each experiment were also calculated. The presence of either PEG or PPG additives has no marked effect on the yield, with similar values calculated for the additive experiments and the pure ethyl acetate control run (see Supporting Information)
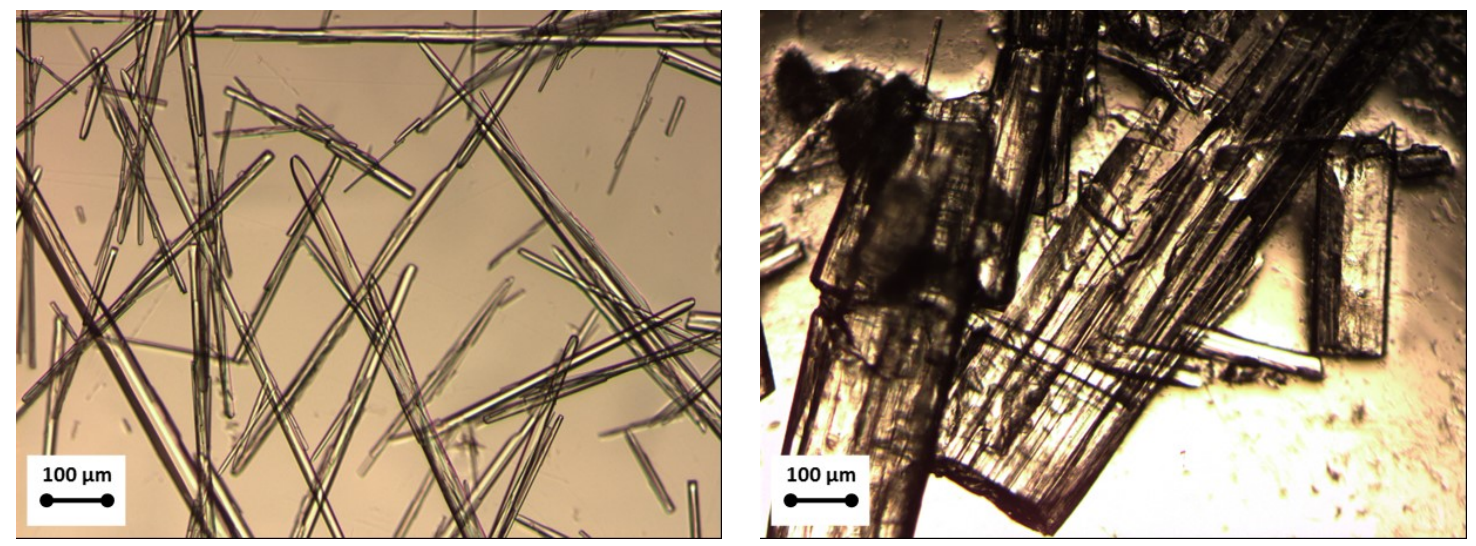

Figure 8. Crystals of lovastatin formed by temperature cycling crystallization studies in ethyl acetate at a concentration of $3.2 \% \mathrm{~m} / \mathrm{m}$, in the presence of $0.5 \%$ polymer additive with overhead stirring, left $=$ PEG polymer, right $=$ PPG polymer

Crystal Face Indexing. A representative single crystal sample from each crystallization vial was subject to a SCXRD unit cell determination, which further confirmed that the solid form remains unchanged under both temperature cycling conditions and on the addition of $0.5 \%$ polymer additive. Crystal face indexing analysis was then performed for each sample, enabling the 
identification of the natural crystal faces. Figure 9 compares the lovastatin crystal habits for each set of conditions.
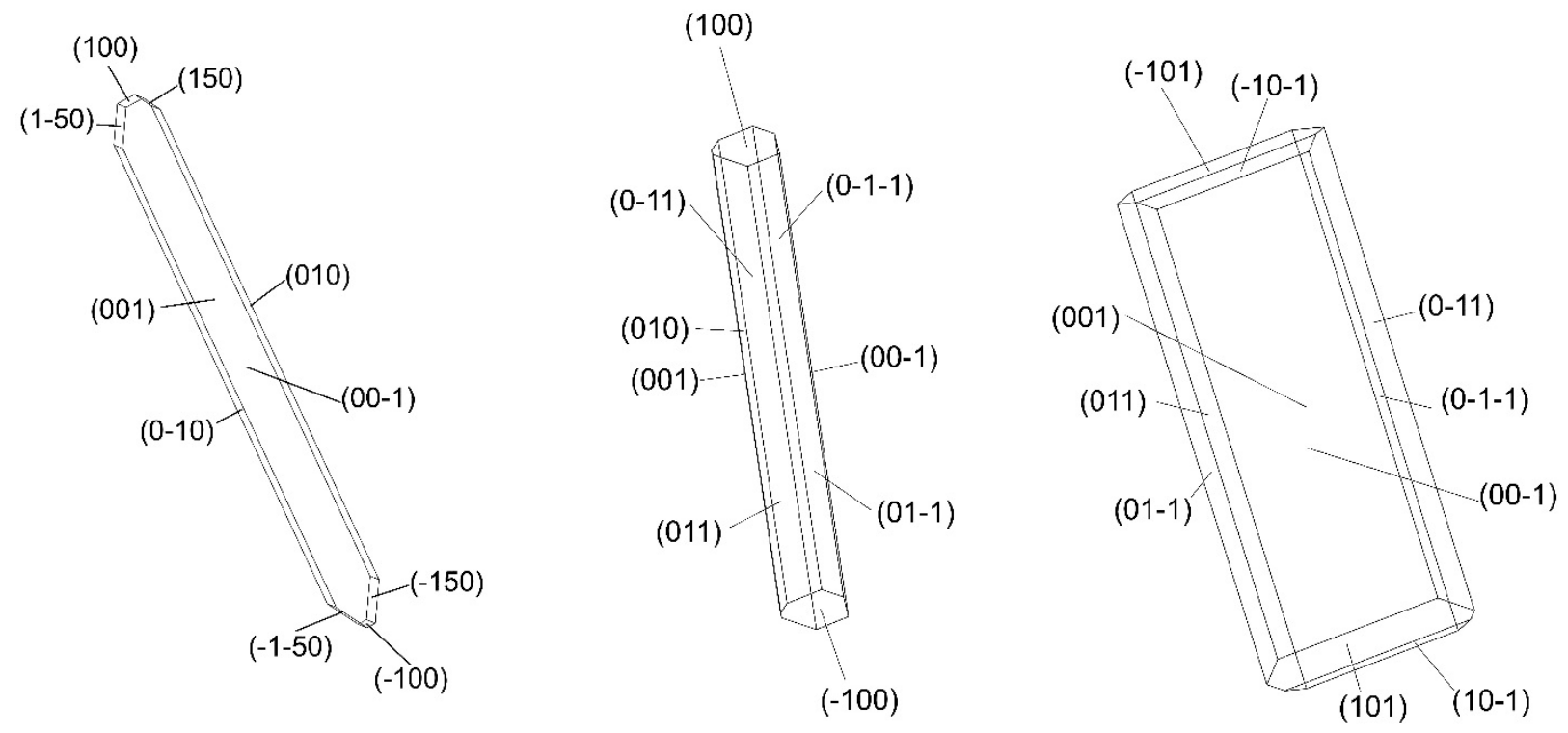

Figure 9. Natural crystal faces of lovastatin needles grown from ethyl acetate by temperature cycling methods, determined by crystal face-indexing methods; left: in the presence of pure ethyl acetate only, center: on addition of $0.5 \%$ PEG, right: on addition of $0.5 \%$ PPG. Crystal ARs are 22.39 (pure ethyl acetate, left), 28.67 (0.5\% PEG, center), and 5.86 (0.5\% PPG, right).

The longest axis of all crystals runs parallel to the crystallographic $a$-axis, as observed for the needles formed by evaporative methods, and both sets of needles in Figure 9 are capped by [100] faces. This indicates that there is still significantly fast growth parallel to these hydrophobic crystal faces, in line with the results of previous computational studies, ${ }^{45}$ regardless of the presence of either polymer additive.

The crystal faces of the needles formed by cycling in pure ethyl acetate (Figure 8, left) are similar to the needles formed by evaporation of ethyl acetate solution (as shown in Figure 4, right), excepting that the prominent equatorial faces are different following temperature cycling. The 
faces with largest relative area are now the [001] set, generating a slightly flatter needle than those observed from slow evaporation. Crystal face indexing confirms the thin needle-like habit of the lovastatin crystals grown in the presence of PEG. These needles again have different prominent equatorial faces, in comparison to the needles grown from pure ethyl acetate, with growth of the [011] and [0-11] sets apparently promoted in the presence of the hydrophilic polymer to produce a more hexagonal-shaped cross-section. The thin PEG needles also display more squared-off [100] needle capping faces, similar to the thin needles grown by slow evaporation from acetone/water (Figure 4, left). The plate-like crystals formed in the presence of PPG also show prominent [011] and [0-11] faces, but the key reason for the observed transformation to a plate-like habit is significant growth in the [010], or crystallographic $b$-direction. The faces with largest relative area are the [001] faces and there is little growth perpendicular to these, along the $c$-axis direction. At the plate capping faces there is now no longer evidence of the [100] set, instead bevelled capping edges are observed, formed by the [101] and [10-1] sets. Interestingly, these faces are exactly those predicted as capping faces by contact-surface calculations in the recent literature. ${ }^{45}$

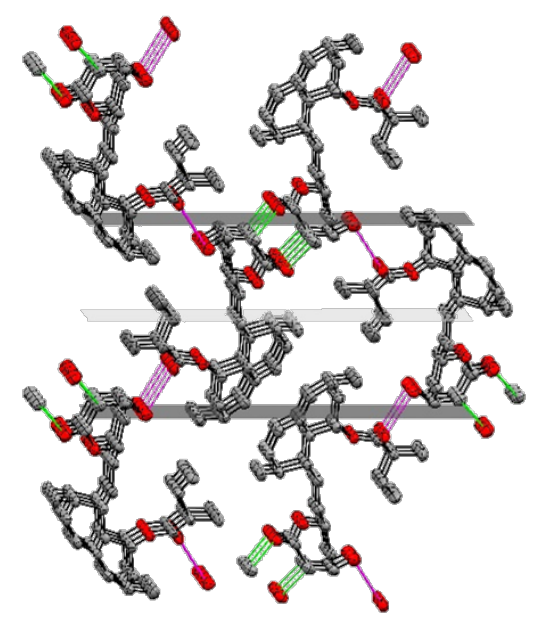

Figure 10. Plane slice through the lovastatin crystal structure (CEKBEZ01), showing the prominent functional groups intersected by the [010] crystal faces, formal O-H...O hydrogen 
bonds represented in magenta, weak $\mathrm{C}-\mathrm{H} . . . \mathrm{O}$ hydrogen bonds represented in green and hydrogen atoms removed for clarity

The crystal face indexing analysis indicates that the hydrophobic PPG polymer may help to limit crystal growth perpendicular to the hydrophobic [100] faces (i.e. limiting growth along the long needle axis to promote an improved aspect ratio). To better rationalise why the presence of PPG and PEG polymer additives promote such a difference in the lovastatin crystal habit, an overlay of the key Miller plane slices with the underlying lovastatin crystal structure was conducted in the CCDC software Mercury. ${ }^{46}$ Figure 10 shows that the [010] planes (prominent for the PPG plates but absent for the thin PEG needles) intersect both formal O-H...O and weaker C-H...O hydrogen bonding interactions, and so these faces are likely to be hydrophilic. Thus, the lack of growth along this $b$-axis direction (perpendicular to the [010] faces) in the presence of PEG additive may indicate that this hydrophilic polymer is interacting with these hydrophilic faces and helping to block to approach of new lovastatin molecules, thereby limiting the formation of these key hydrogen bonding interactions. By contrast, the improved, plate-like crystal habit will result from the promotion of these hydrogen bonding interactions in the presence of hydrophobic PPG.

Temperature cycling experiments with varied PPG additive concentration. Focussing in on the hydrophobic PPG additive as the most promising candidate for lovastatin crystal habit control, a series of further screening studies were conducted in which the PPG additive concentration was varied from $0.5 \% \mathrm{wt} / \mathrm{wt}$ of polymer-to-lovastatin, to $1 \%, 5 \%$ and $10 \%$ of PPG. These experiments showed that the most promising crystals were obtained with lower PPG content. As the amount of PPG was increased, a marked decrease in crystal quality is observed with increasingly more irregular morphologies produced, particularly at 5 and $10 \% \mathrm{wt} / \mathrm{wt}$ of PPG. PLM 
images of all product crystals from this screen are included in the Supporting Information, alongside PXRD and DSC measurements that confirm no change in the solid form occurs that could account for the observed change in the crystal appearance. As such, an additive concentration level of $0.5 \%$ PPG was used exclusively in all further crystallization studies.

Temperature cycling experiments at $6.1 \% \mathrm{~m} / \mathrm{m}$. A second series of temperature cycling experiments investigated the effect of widening the temperature cycling regime on the crystal habit. In these experiments, the crystals were cycled between a high temperature of $50{ }^{\circ} \mathrm{C}$ and low temperature of $15^{\circ} \mathrm{C}$ (see Figure $2 \mathrm{~b}$ ). Using the literature and measure solubility data as a guideline, the concentration of lovastatin in ethyl acetate was also raised for these experiments, to $6.1 \% \mathrm{~m} / \mathrm{m}$ (equating to a saturation concentration at $50{ }^{\circ} \mathrm{C}$ ).

New temperature cycling experiments were then run using this regime, both in the presence of $0.5 \%$ PPG additive and a pure ethyl acetate control crystallization. The crystallization yields are similar to those of the previous temperature cycling runs (in the region of $75-81 \%$, see Supporting Information), and again there is no obvious influence of the polymer additive on these values. PLM images of the resulting crystals are provided in Figure 11. The implementation of a wider temperature cycling regime appears to promote the growth of much larger lovastatin crystals, with many product crystals measured to be up to $1 \mathrm{~mm}$ in length. These larger crystals also show clear differences in the needle-capping ends of the crystals grown in the presence of PPG compared to the control study without additive, which are assessed by both PLM (Figure 11) and crystal face indexing methods (Figure 12). 
The crystals grown from pure ethyl acetate display bevelled capping edges, similar to those observed at lower lovastatin concentration and in-line with the predicted lovastatin needle morphology from prior studies. ${ }^{45}$ By contrast, crystals grown in the presence of PPG have squaredoff capping edges, and the crystal faces allocated by face-indexing methods match well to the more plate-like crystals observed at lower concentration levels (see Figure 9 for comparison).
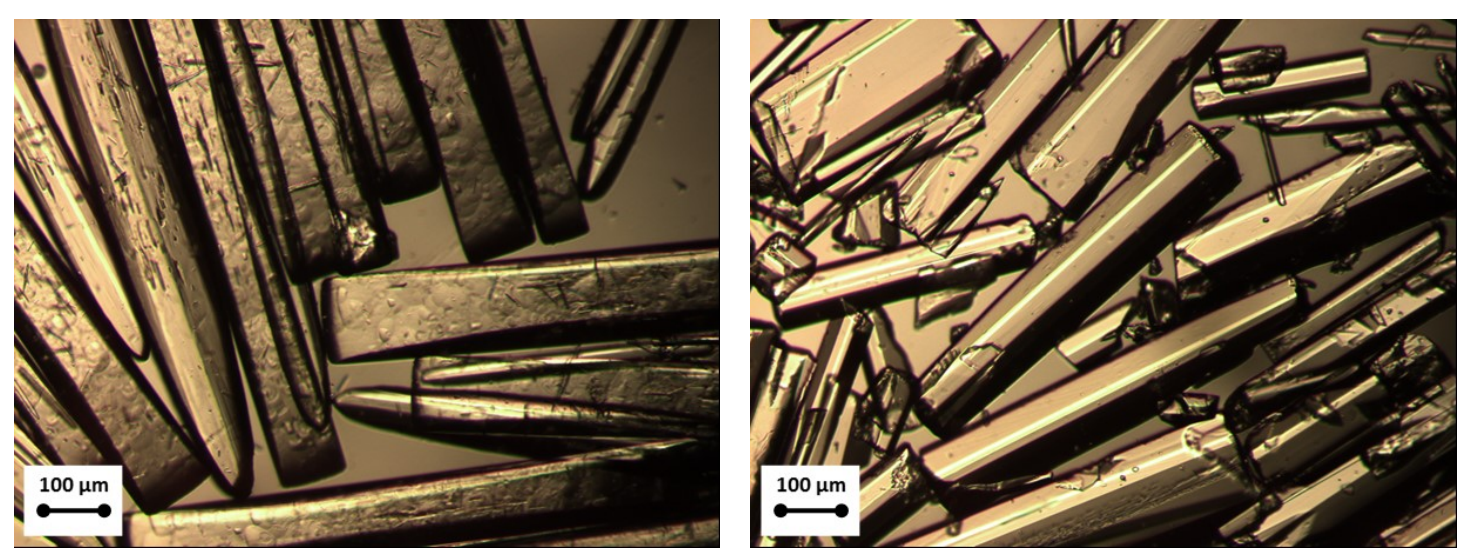

Figure 1. Crystals of lovastatin formed by temperature cycling crystallization studies in ethyl acetate at a concentration of $6.1 \% \mathrm{~m} / \mathrm{m}$ with overhead stirring, left $=$ no polymer, right $=$ in the presence of $0.5 \%$ PPG polymer additive 

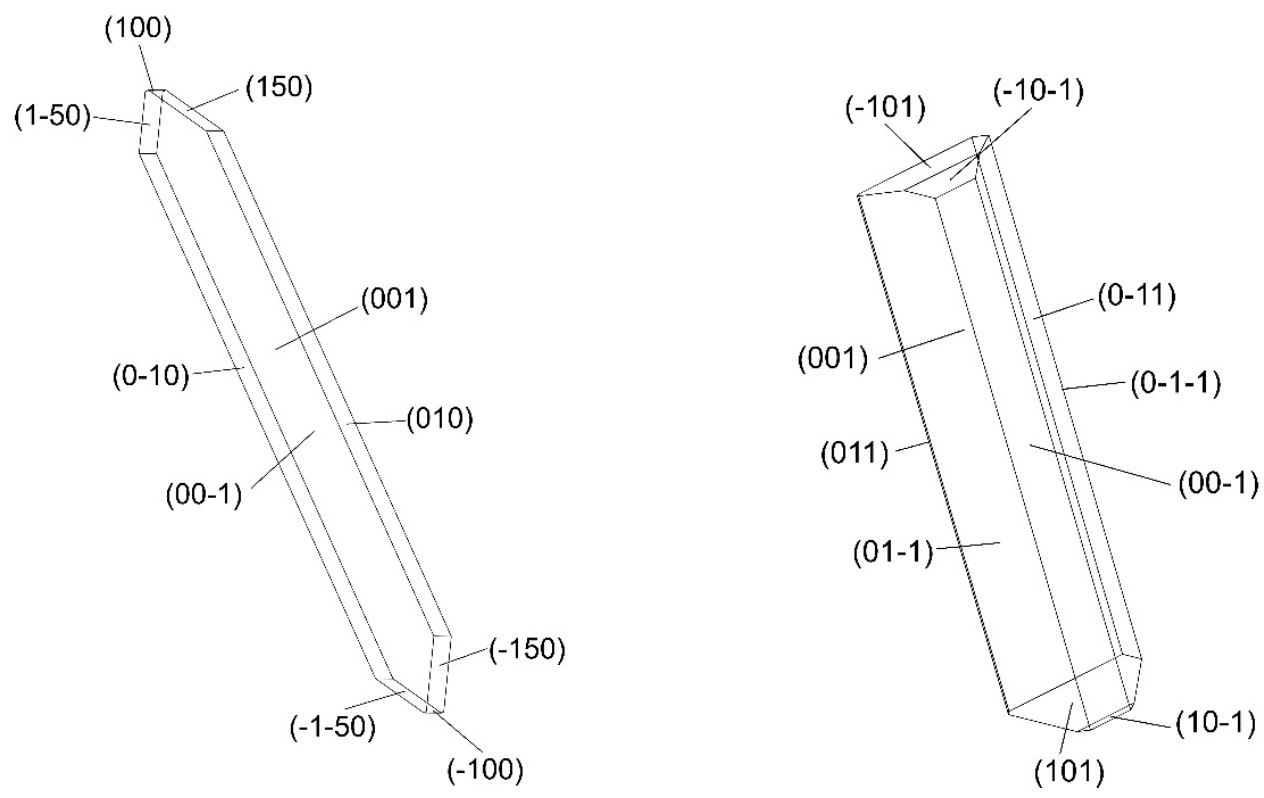

Figure 2. Natural crystal faces of lovastatin needles grown from ethyl acetate by temperature cycling methods at a concentration of $6.1 \% \mathrm{~m} / \mathrm{m}$, determined by crystal face indexing methods, left: pure ethyl acetate only, right: in the presence of $0.5 \%$ PPG polymer additive. Crystal ARs are 9.79 (pure ethyl acetate, left) and 4.88 (0.5\% PPG, right).

\section{CONCLUSIONS}

This investigation has shown how the crystal habit of lovastatin may be controlled both through the choice of crystallization solvent, the crystallization method and via the inclusion of non-sizematched soluble polymer additives. The choice of crystallization solvent is shown to have a minor effect on lovastatin needle habit, with moderately hygroscopic ethyl acetate producing thicker needles than other, more polar, solvent systems. Crystallization in the presence of non-sizedmatched PEG and PPG polymer additives has a marked effect on lovastatin crystal morphology, with hydrophilic PEG promoting the formation of even longer and thinner needles, possibly due to blocking of the hydrophilic equatorial faces of the needle and thereby promoting further growth 
along the long needle axis (crystallographic a-axis direction). By contrast, inclusion of hydrophobic PPG appears to limit the growth along the long needle axis, helping to change the habit toward more plate-like crystals. The choice of crystallization method (either evaporation or temperature cycling) and the experi- ment design also have a marked effect on crystal size, shape, and the reproducibility of the method, with saturation concentration and the width of the temperature cycle shown to be particularly influential.

Although these methods are shown to work well at a small scale, attempts to scale-up the temperature cycling PPG additive crystallization to larger volumes $(100$ and $150 \mathrm{~mL})$ resulted in a complete loss of crystal habit control. Further work, involving the use of process analytical techniques (PAT) and feedback control, is required to overcome scale-up issues before these methods could be implemented for a real pharmaceutical crystallization process, and this work will be addressed in a subsequent publication.

\section{ASSOCIATED CONTENT}

Supporting Information. The Supporting Information is available free of charge on the ACS Publications Website at DOI: https://pubs.acs.org/doi/10.1021/acs.cgd.0c00470.

Recorded PXRD and DSC data, MSZW data, PLM images and experiment yield calculations (PDF file format).

\section{AUTHOR INFORMATION}

\section{Corresponding Author}


*Dr Lauren E. Hatcher, Department of Chemistry, University of Bath, BA2 1NN, UK. Email: l.e.hatcher@bath.ac.uk

\section{ORCID}

Lauren E. Hatcher: https://orcid.org/0000-0002-1549-9727

Notes

The authors declare no competing financial interest.

\section{ACKNOWLEDGMENTS}

The authors thank the UK Engineering and Physical Research Council for funding this research (EPSRC; grant no. EP/P006965/1), and the University of Bath for studentship funding for PP. Powder X-ray diffraction facilities were provided through the Material and Chemical Characterisation Facility $\left(\mathrm{MC}^{2}\right)$ at the University of Bath (http://go.bath.ac.uk/mc2). Solubility measurement facilities were provided through the CMAC Future Manufacturing Research Hub at the Technology and Innovation Centre, University of Strathclyde (https://www.cmac.ac.uk/).

\section{REFERENCES}

(1) Moore, R. N.; Bigam, G.; Chan, J. K.; Hogg, A. M.; Nakashima,T. T.; Vederas, J. C. Biosynthesis of the hypocholesterolemic agent mevinolin by Aspergillus terreus. Determination of the origin of carbon, hydrogen, and oxygen atoms by carbon-13 NMR and mass spectrometry. J. Am. Chem. Soc. 1985, 107, 3694-3701.

(2) Alberts, A. W.; Chen, J.; Kuron, G.; Hunt, V.; Huff, J.; Hoffman, C.; Rothrock, J.; Lopez, M.; Joshua, H.; Harris, E.; Patchett, A.; Monaghan, R.; Currie, S.; Stapley, E.; Albers-Schonberg, G.; Hensens, O.; Hirshfield, J.; Hoogsteen, K.; Liesch, J.; 
Springer, J. Mevinolin: a highly potent competitive inhibitor of hydroxymethylglutaryl- coenzyme A reductase and a cholesterol-lowering agent. Proc. Natl. Acad. Sci. U. S. A. 1980, 77, 3957-3961.

(3) Mulder, K. C. L.; Mulinari, F.; Franco, O. L.; Soares, M. S. F.; Magalhãe, B. S.; Parachin, N. S. Lovastatin production: From molecular basis to industrial process optimization. Biotechnol. Adv. 2015, 33, 648-665.

(4) Hirama, M.; Iwashita, M. Total synthesis of (+)-monacolin K (mevinolin). Tetrahedron Lett. 1983, 24, 1811-1812.

(5) Lin, L.; Wu, S.; Li, Z.; Ren, Z.; Chen, M.; Wang, C. High Expression Level of mok E Enhances the Production of Monacolin K in Monascus. Food Biotechnol. 2018, $32,35-46$.

(6) Endo, A.; Negishi, Y.; Iwashita, T.; Mizukawa, K.; Hirama, M. Biosynthesis of ML-236B (compactin) and monacolin K. J. Antibiot. 1985, 38, 444-448.

(7) Amidon, G. L.; Lennernä̈, H.; Shah, V. P.; Crison, J. R. A Theoretical Basis for a Biopharmaceutic Drug Classification: The Correlation of in Vitro Drug Product Dissolution and in Vivo Bioavailability. Pharm. Res. 1995, $12,413-420$.

(8) Amidon, K. S.; Langguth, P.; Lennernä̈, H.; Yu, L.; Amidon, G.

L. Bioequivalence of Oral Products and the Biopharmaceutics Classification System: Science, Regulation, and Public Policy. Clin. Pharmacol. Ther. 2011, 90, 467-470.

(9) Zhou, J.; Zhou, D. Improvement of oral bioavailability of lovastatin by using nanostructured lipid carriers. Drug Des., Dev. Ther. 2015, 9, 5269-5275.

(10) Chen, C.-H.; Yang, J.-C.; Uang, Y.-S.; Lin, C.-J. Improved dissolution rate and oral bioavailability of lovastatin in red yeast rice products. Int. J. Pharm. 2013, $444,18-24$.

(11) Suresh, G.; Manjunath, K.; Venkateswarlu, V.; Satyanarayana, Preparation, characterization, and in vitro and in vivo evaluation of lovastatin solid lipid nanoparticles. AAPS PharmSciTech 2007, 8, E162-E170. 
(12) Variankaval, N.; Cote, A. S.; Doherty, M. F. From form to function: Crystallization of active pharmaceutical ingredients. AIChE J. 2008, 54, 1682-1688.

(13) Davey, R.; Garside, J. From Molecules to Crystallizers; Oxford University Press, 2000.

(14) Klapwijk, A. R.; Simone, E.; Nagy, Z. K.; Wilson, C. C. Tuning Crystal Morphology of Succinic Acid Using a Polymer Additive. Cryst. Growth Des. 2016, 16, 4349-4359.

(15) Simone, E.; Klapwijk, A. R.; Wilson, C. C.; Nagy, Z. K. Investigation of the Evolution of Crystal Size and Shape during Temperature Cycling and in the Presence of a Polymeric Additive Using Combined Process Analytical Technologies. Cryst. Growth Des. 2017, 17, 1695-1706.

(16) Lovette, M. A.; Muratore, M.; Doherty, M. F. Crystal shape modification through cycles of dissolution and growth: Attainable regions and experimental validation. AIChE J. 2012, 58, $1465-1474$.

(17) Wu, Z.; Yang, S.; Wu, W. Application of temperature cycling for crystal quality control during crystallization. CrystEngComm 2016, 18, 2222-2238.

(18) Besenhard, M. O.; Neugebauer, P.; Ho, C.-D.; Khinast, J. G. Crystal Size Control in a Continuous Tubular Crystallizer. Cryst. Growth Des. 2015, 15, 1683-1691.

(19) Su, Q.; Nagy, Z. K.; Rielly, C. D. Pharmaceutical crystallisation processes from batch to continuous operation using MSMPR stages: Modelling, design, and control. Chem. Eng. Process. 2015, 89, 41-53.

(20) Heffernan, C.; Ukrainczyk, M.; Zeglinski, J.; Hodnett, B. K.; Rasmuson, Å. C. Influence of Structurally Related Impurities on the Crystal Nucleation of Curcumin. Cryst. Growth Des. $2018,18,4715-4723$.

(21) Song, R.-Q.; Cölfen, H. Additive controlled crystallization. CrystEngComm 2011, 13, 1249-1276.

(22) Simone, E.; Cenzato, M. V.; Nagy, Z. K. A study on the effect of the polymeric additive HPMC on morphology and polymorphism of ortho-aminobenzoic acid crystals. J. Cryst. Growth 2016, 446, 50-59.

(23) Bodnaŕ, K.; Hudson, S. P.; Rasmuson, Å. C. Stepwise Use of 
Additives for Improved Control over Formation and Stability of Mefenamic Acid Nanocrystals Produced by Antisolvent Precipitation. Cryst. Growth Des. 2017, 17, 454-466.

(24) Reis, N. M.; Liu, Z. K.; Reis, C. M.; Mackley, M. R. Hydroxypropyl Methylcellulose as a Novel Tool for Isothermal Solution Crystallization of Micronized Paracetamol. Cryst. Growth Des. 2014, 14, 3191-3198.

(25) Saleemi, A.; Onyemelukwe, I. I.; Nagy, Z. Effects of a structurally related substance on the crystallization of paracetamol. Front. Chem. Sci. Eng. 2013, 7, 79-87.

(26) Losev, E. A.; Mikhailenko, M. A.; Achkasov, A. F.; Boldyreva, E.V. The effect of carboxylic acids on glycine polymorphism, salt and co-crystal formation. A comparison of different crystallisation techniques. New J. Chem. 2013, 37, 1973-1981.

(27) Simone, E.; Steele, G.; Nagy, Z. K. Tailoring crystal shape and polymorphism using combinations of solvents and a structurally related additive. CrystEngComm 2015, 17, 9370-9379.

(28) Benages-Vilau, R.; Calvet, T.; Pastero, L.; Aquilano, D.; Cuevas- Diarte, M. À. Morphology Change of Nitratine $\left(\mathrm{NaNO}_{3}\right)$ from Aqueous Solution, in the Presence of $\mathrm{Li}^{+}$and $\mathrm{K}^{+}$Ions. Cryst. Growth Des. 2015, 15, 5338-5344.

(29) Polat, S.; Sayan, P. Kinetic analysis and polymorphic phase transformation of glycine in the presence of lauric acid. J. Cryst. Growth 2018, 481, 71-79.

(30) Trasi, N. S.; Taylor, L. S. Effect of Additives on Crystal Growth and Nucleation of Amorphous Flutamide. Cryst. Growth Des. 2012, 12, 3221-3230.

(31) De Meirleir, N.; Broeckx, W.; Van Puyvelde, P.; De Malsche, W. Surfactant Assisted Emulsion Crystallization of Hydrogenated Castor Oil. Cryst. Growth Des. 2015, 15, $635-641$.

(32) Chen, J.; Ormes, J. D.; Higgins, J. D.; Taylor, L. S. Impact of Surfactants on the Crystallization of Aqueous Suspensions of Celecoxib Amorphous Solid Dispersion Spray Dried Particles. Mol. Pharmaceutics 2015, 12, 533-541.

(33) Chavan, R. B.; Thipparaboina, R.; Kumar, D.; Shastri, N. R. Evaluation of the inhibitory potential of HPMC, PVP and HPC polymers on nucleation and crystal growth. RSC Adv. 2016, 6, 77569-77576. 
(34) Cölfen, H. Double-Hydrophilic Block Copolymers: Synthesis and Application as Novel Surfactants and Crystal Growth Modifiers. Macromol. Rapid Commun. 2001, 22, 219-252.

(35) Berkovitch-Yellin, Z.; Addadi, L.; Idelson, M.; Lahav, M.; Leiserowitz, L. Controlled Modification of Crystal Habit via "Tailor- Made" Impurities. Application to Benzamide. Angew. Chem., Int. Ed. Engl. 1982, 21, 1336-1345.

(36) Davey, R.; Fila, W.; Garside, J. The influence of biuret on the growth kinetics of urea crystals from aqueous solutions. J. Cryst. Growth 1986, 79, 607-613.

(37) Tian, F.; Baldursdottir, S.; Rantanen, J. Effects of Polymer Additives on the Crystallization of Hydrates: A Molecular-Level Modulation. Mol. Pharmaceutics 2009, 6, 202-210.

(38) Thomas, L. H.; Wales, C.; Zhao, L.; Wilson, C. C. Paracetamol Form II: An Elusive Polymorph through Facile Multicomponent Crystallization Routes. Cryst. Growth Des. 2011, 11, 1450-1452.

(39) Kuvadia, Z. B.; Doherty, M. F. Effect of Structurally Similar Additives on Crystal Habit of Organic Molecular Crystals at Low Supersaturation. Cryst. Growth Des. 2013, 13, 1412-1428.

(40) Yani, Y.; Chow, P. S.; Tan, R. B. H. Molecular Simulation Study of the Effect of Various Additives on Salbutamol Sulfate Crystal Habit. Mol. Pharmaceutics 2011, 8, 1910-1918.

(41) Xie, S.; Poornachary, S. K.; Chow, P. S.; Tan, R. B. H. Direct Precipitation of Micron-Size Salbutamol Sulfate: New Insights into the Action of Surfactants and Polymeric Additives. Cryst. Growth Des. 2010, 10, 3363-3371.

(42) Poornachary, S. K.; Chia, V. D.; Yani, Y.; Han, G.; Chow, P. S.; Tan, R. B. H. Anisotropic Crystal Growth Inhibition by Polymeric Additives: Impact on Modulation of Naproxen Crystal Shape and Size. Cryst. Growth Des. 2017, 17, 4844-4854.

(43) Othman, R.; Vladisavljevic,G. T.; Simone, E.; Nagy, Z. K.; Holdich, R. G. Preparation of Microcrystals of Piroxicam Mono- hydrate by Antisolvent Precipitation via Microfabricated Metallic Membranes with Ordered Pore Arrays. Cryst. Growth Des. 2017, 17, 6692-6702.

(44) Munk, T.; Baldursdottir, S.; Hietala, S.; Rades, T.; Kapp, S.; Nuopponen, M.; 
Kalliomak K.; Tenhu, H.; Rantanen, J. Crystal Morphology Modification by the Addition of Tailor-Made Stereo- controlled Poly(N-isopropyl acrylamide). Mol. Pharmaceutics 2012,9, 1932-1941.

(45) Turner, T. D.; Hatcher, L. E.; Wilson, C. C.; Roberts, K. J. Habit Modification of the Active Pharmaceutical Ingredient Lovastatin Through a Predictive Solvent Selection Approach. J. Pharm. Sci. 2019, 108, 1779-1787.

(46) Macrae, C. F.; Bruno, I. J.; Chisholm, J. A.; Edgington, P. R.; McCabe, P.; Pidcock, E.; Rodriguez-Monge, L.; Taylor, R.; van de Streek, J.; Wood, P. A. Mercury CSD 2.0 - new features for the visualization and investigation of crystal structures.J. Appl. Crystallogr. 2008, 41, 466-470.

(47) Tan, B.; Melius, P.; Ziegler, P. A Simple Gas Chromatographic Method for the Study of Organic Solvents: Moisture Analysis, Hygroscopicity, and Evaporation. J. Chromatogr. Sci. 1982, 20, 213-217.

(48) Kawai, F. Biodegradation of Polyethers (Polyethylene Glycol, Polypropylene Glycol, Polytetramethylene glycol, and Others). In Biopolymers Online, Steinbüchel, A., Ed.; Wiley, 2005.

(49) Zhang, J. Switchable and Responsive Surfaces and Materials for Biomedical Applications; Elsevier Science, 2014.

(50) Sun, H.; Gong, J.-b.; Wang, J.-k. Solubility of Lovastatin in Acetone, Methanol, Ethanol, Ethyl Acetate, and Butyl Acetate between 283 and 323 K. J. Chem. Eng. Data 2005, 50, 1389-1391. 